\title{
A língua do outro e a nossa: Política, tradução e psicanálise
} PAULO SÉRGIO DE SOUZA JR. I

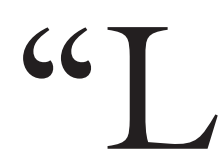

ÍNGUA é mais que sangue". É com essa frase, escrita pelo filósofo e tradutor judeu-alemão Franz Rosenzweig, falecido em 1929, que inicio este breve texto 90 anos depois. O falecimento desse homem, que viveu entre línguas e entre tradições - morte contemporânea à dita "Grande Depressão" (A Crise de 1929) -, livrou-o de testemunhar as milhares de outras mortes que marcariam a Europa nos anos seguintes: mortes físicas, decerto, como se sabe, mas também mortes simbólicas que vinham se acumulando antes mesmo da Segunda Guerra.

A esse respeito podemos citar, já no início do século, a limitação do ingresso de judeus em várias universidades europeias, mas também a queima de livros (1933); a proibição do ingresso em cursos superiores de prestígio (1934); a proibição dos casamentos mistos $^{1}$ (1935); a perda da cidadania alemã (1936); a proibição de frequentar diversos locais públicos (1938); o confisco de rádios (1939), aparelhos telefônicos (1940); a proibição do uso de telefones públicos (1941); o impedimento do ingresso em escolas (1942) e as contínuas deportações (1943-1945). O idioma iídiche, não surpreendentemente, foi proibido em diversos países. Era como se não bastasse dizimar a carne sem, antes, ter garroteado bem o espírito. Língua é mais que sangue.

$\mathrm{O}$ discurso nazista, geralmente considerado o paroxismo moderno da colonização do outro - caminhando numa espécie de crescente que vai da negligência ativa à sistemática aniquilação - serve aqui para pensarmos uma época, mas também uma história que se repete como farsa. E já que nos é vedado conhecer a origem (veto que tentamos mitigar com os tantos mitos que criamos para dela dar conta), aquilo que se teria realizado primeiro como tragédia guarda em si certo parentesco justamente com o mítico, sendo o farsesco o que ainda temos de mais palpável - mas, nem por isso, menos real. Recomeça-se, então, incessantemente e desde sempre. Esquecimento e memória. É o inseto que troca repetidamente a sua casca quando esta já não lhe cabe; inseto com o qual nunca nos deparamos para além das estruturas ocas que ele deixa pelo caminho - aquilo que lhe sobra. Se no princípio era o Verbo, então há de se pensar que a nossa lida, humana, é sempre com a perda e com o eco.

"Língua é mais que sangue." É com essa frase que Victor Klemperer [1881-1960] inicia o compilado das notas tomadas entre 1933 e 1945, publicado em 1947, intitulado Lingua Tertii Imperii: anotações de um filólogo. Roma- 
nista e professor universitário de origem judaica, convertido ao protestantismo, Klemperer não imaginava que a Alemanha pudesse se tornar, em pleno século $\mathrm{XX}$, um país totalitário; acreditava que não haveria mais perseguições religiosas ao povo judeu depois da Inquisição espanhola, e por essas e outras não cogitou seriamente deixar o país. País que o perseguirá e no qual conseguiu sobreviver apenas em razão do empenho da pianista, pintora e tradutora Eva Schlemmer [1882-1951]: a esposa ariana, que jamais saiu do lado do marido, impedindo a sua morte pelas forças hitleristas.

Nesse seu livro, imortalizado pelas iniciais do título, LTI, é do latim que Klemperer importa os termos para nomear seu objeto de estudo ao longo dos anos de penúria: Lingua Tertii Imperii (A Linguagem do Terceiro Reich). Não se trata, contudo, de um cacoete de especialista, tampouco de um rompante de erudição. Antes mesmo, de uma escolha que reencena ironicamente a presença e a serventia, no discurso nazista, da língua do outro. Segundo Klemperer, "poucas palavras foram cunhadas pelo Terceiro Reich, talvez nenhuma. A linguagem nazista usa empréstimos do estrangeiro e absorve muito do alemão pré-hitlerista. Mas altera o sentido das palavras e a frequência de seu uso". Ela "envenena palavras e formas sintáticas. Adapta a língua ao seu sistema terrível e, com ela, conquista o meio de propaganda mais poderoso - ao mesmo tempo o mais público e o mais secreto" (Klemperer, 2009, p.56). Língua é mais que sangue.

A colonização do outro passar pela língua não é algo novo. Ela passar batido, tampouco. $\mathrm{O}$ ideal que presidiu a formação dos Estados modernos nacionais no século XV (um deus, um rei, uma lei, mas também uma língua) teve como resultado a repressão da diversidade linguística em países como a França, por exemplo - em que atualmente, para línguas como o bretão e o provençal, restou um lugar quase pitoresco, bem como a qualificação dada pela Unesco de idiomas em sério risco de extinção.

No Brasil não seria diferente: o Diretório dos Índios, elaborado em 1755 por D. José I, rei de Portugal - e tornado público dois anos depois através do famigerado Marquês de Pombal - proibiu aos povos indígenas aquilo que, para o colonizador, era obsceno: a nudez, as habitações coletivas e o uso da língua geral (de base majoritariamente tupi: "a língua mais usada na costa do Brasil", como dizia José de Anchieta no título de sua gramática ${ }^{2}$ ). O desacato, naturalmente, era punido - acabando, por vezes, em morte. E o eco disso se percebe muitos anos depois, com a campanha de nacionalização lançada por Getúlio, quando em 1939 se proibiu não apenas a impressão de jornais em línguas estrangeiras, mas também falá-las em público, obscenas que se tornaram. Língua é mais que sangue.

O nacionalismo, no entanto, não redimiu nosso idioma. Se, por um lado, desde a Carta de Pero Vaz e as primeiras descrições - feitas por José de Anchieta, Pero de Magalhães Gândavo, entre outros - entendeu-se comprovar linguisticamente o déficit que já se presumia encontrar nos povos daqui (a ausência de alguns fonemas no tupi materializaria, aos ouvidos portugueses, a ausência 
de um poder religioso e real, e também de uma administração jurídica entre os autóctones), por outro, o português brasileiro carregaria no futuro a pecha de uma língua menor, ritmando esse adjetivo sempre a contrapé - a tônica, não por acaso, recaindo no elemento europeu desse binômio.

Assim, vítimas de patriotismos estranhos que nos privaram do multilinguismo, fizeram de nós não apenas falantes convictos de uma língua só, mas de uma mesolíngua - por assim dizer -, como se já não bastasse estarmos tão distantes não apenas das 274 línguas indígenas que resistem ainda faladas em território nacional, ${ }^{3}$ muitas delas em sério risco de extinção, mas também de costas viradas para as variedades hispânicas faladas nos países com que temos fronteira; e, sobretudo, desconectados do próprio processo de crioulização pelo qual passou o idioma que chamamos de nosso - sem querer reconhecer os nós que nele se fazem presentes, encorpando-o e incrementando-o com os seus matizes, desvios e heranças. Língua é mais que sangue.

Parece inescapável, portanto, o fato de que aquilo que se produz em língua estrangeira e chega ao Brasil tenha de se haver com os efeitos desse somatório de depreciações, autodepreciações e apagamentos; de consolidações sucessivas de silenciamentos e vira-latismos. Evidentemente, isso não nos impede de exercer a nossa bravata com relação a outros países (vizinhos ou não) que consideramos menores e piores que nós, ou línguas que achamos por bem considerar menos complexas (seja lá o que isso signifique) ou supostamente desprovidas de sandade. No entanto, tampouco nos livra de ver, numa certa Europa, tácita ou franca superioridade; ou de supor, de uma América que está mais ao Norte, que ela estaria sempre por cima.

Dito isso: a nós, psicanalistas, não nos escapa o fato - ou, pelo menos, os efeitos do fato - de que a psicanálise é uma teoria importada. Cumpre indagar, então, o quanto nós, supostamente interessados pela linguagem de um modo particular, nos importamos com isso. Em certo sentido, na esteira do gesto derridiano de nomear a América Latina - realizado em sua brilhante conferência sobre o que é ali chamado de "geopsicanálise" (Derrida [1981]) -, seria importante que nos perguntássemos em conjunto: quando, em se tratando de psicanálise, nomeamos a América Latina, o Brasil, em que língua o fazemos?

A obra de Freud, escrita em seu alemão com sotaque austríaco, pagou pedágios de tradução indireta por muitas décadas no país, capitaneada pela evidente falta de honestidade editorial, estampada em dourado nas capas duras de seus caríssimos volumes que adornaram estantes de tantos escritórios médicos, jurídicos e bibliotecas particulares de intelectuais abastados Brasil afora. Só depois começou a ser traduzida diretamente para o português brasileiro. Não se pode dizer, assim, que tenhamos propriamente entrado em contato com a língua de Freud - administrada a conta-gotas, entre parênteses, nos trabalhos que faziam questão (nem sempre pelas razões mais nobres, é preciso dizer) de trazer a tiracolo o conceito na língua de origem. 
Mas o fato é que, com a Segunda Guerra, como aponta Jean-Claude Milner (Lévy; Reznik, 2014), passa-se do alemão - que ocupava o lugar de língua do pensamento desde o final do século XVIII - ao francês - língua em que as novas ideias seriam então conjugadas ("Sartre, Merleau-Ponty, o estruturalismo nascente...”). E com o francês, sim, estivemos em contato considerável: quer pela própria escolarização da época; quer pelos brasileiros que estiveram em formação na França nas décadas de 1960/1970 - alguns dos quais seriam porta-vozes do lacanismo no Brasil nos anos seguintes -; quer pelas traduções que começaram a ser feitas diretamente do francês, ainda que de forma pouco sistemática, no início, e por estudiosos sem formação ou real traquejo para o ofício tradutório.

O resultado se deixa notar logo nas primeiras páginas: quando abrimos boa parte da literatura psicanalítica nacional traduzida da língua francesa, sobretudo os textos de Lacan, é custoso não esbarrar em construções e vocabulários mal ajambrados, em textos que muitas vezes têm a sua leitura dificultada pelo fato de que os erros de tradução se acumulam e se esparramam pelas beiradas; e que a hesitação constante em traduzir efetivamente produz, por exemplo, fenômenos curiosíssimos como a escolha de "semblante" (que é sinônimo de "rosto", "fisionomia") para traduzir semblant (que, em francês, denota "aparência enganosa", "simulacro"). Isso para ficarmos apenas com o que está na cara. Língua é mais que sangue.

Ora, "quais as razões para preferir a sonoridade da palavra estrangeira, tão ressoante? - pergunta Klemperer. "Em primeiro lugar”, responde ele, “a própria sonoridade. Mas, se procurarmos os diferentes motivos até o último detalhe, descobriremos que também há o desejo de encobrir coisas indesejáveis" (Klemperer, 2009, p.382). E que coisas seriam essas? Para essa pergunta arrisco aqui um arremedo de resposta, um simulacro, redizendo o que muito já se disse: há certa dimensão de perda no próprio ato de subjetivar um texto na língua para a qual se traduz.

Bem, sobre isso já correu muita tinta, não há como negar; mas também é preciso dizer que isso se deu quase sempre na chave que não abre as melhores portas: a da intraduzibilidade, que equipara tradução a traição. "Tradutor, traidor" é o que diz o rancoroso adágio italiano, cúmplice do original ciumento - e, convenhamos, um tanto sexista -, que remói as traduções como belles infidèles ("bonitinhas, mas ordinárias", em francês). A perda, no entanto, conviria ser localizada noutro lugar: menos na tradução, como algo que estaria em débito, e mais no próprio reconhecimento de que o original não está com tudo isso, e ele é menos do que se esperava ser. Sobre o original recai uma barra, e as suas traduções - que nele jazem em potencial, desde sempre - são não apenas prova disso, mas os seus melhores desdobramentos: aquilo que the fornece um horizonte. Afinal, vale lembrar que "original" vem do latim orīgō (de onde também deriva "Oriente", o lugar do qual se diz nascer o Sol), e que "horizonte" vem 
justamente do verbo grego ópí̧ ( horizō: separar, limitar). Horizonte, portanto, como limite, mas também alargamento e expansão. Língua é mais que sangue.

Nesse sentido, relutar é não fazer o luto da palavra estrangeira; velar eternamente a língua do outro, sem revelá-la em sua obscenidade e sem se apropriar disso que ela reserva e está sempre ali pronto para nos colonizar e matar enquanto singularidade e invenção: “A palavra estrangeira”, diz Klemperer (2009, p.382), "impressiona e é tanto mais imponente quanto menos compreendida for $[. .$.$] (Que se pense no efeito da liturgia em latim no serviço religioso católi-$ co)", por exemplo.

Ora, a criança, colonizada pela língua materna, acha por onde revidar tão logo se torna capaz de falar em primeira pessoa, apropriando-se da língua do outro para fazê-la sua. O jogo das aquisições, de primeira ou segunda língua, e o jogo das traduções não são objeto de pacifismo. Quem se aventurou que o diga! Não por acaso, em espanhol, quando alguém quer afirmar que "se vira" falando uma língua, pode bem dizer: "Me defiendo!". E quando se nasce em português, há duas opções para o filhote: ou morre, ou vinga. A diferença, vale dizer, entre o filhote humano e os outros é que o humano termina de ser maturado fora do útero pelos atravessamentos da língua que o coopta, sem deixar grandes opções. A sua vingança passa pela linguagem: é o que nos mostram os experimentos de total privação linguística feitos ao longo da história, em que crianças apartadas da linguagem pereceram miseravelmente. Língua é mais que sangue.

Klemperer $(2009$, p.55) diz que as "palavras podem ser como minúsculas doses de arsênico: são engolidas de maneira despercebida e parecem ser inofensivas; passado um tempo", no entanto, "o efeito do veneno se faz notar". Dito isso, a pergunta insiste: quando, no campo da psicanálise, nomeamos a América Latina, quando nomeamos o Brasil, com que palavras o fazemos?

Se Freud construiu sua teoria a partir da clínica, e nessa teoria encontramos os dizeres saídos da boca de seus pacientes, que dizeres utilizamos nós para construir a nossa? E que palavras hoje se pode dizer que nos envenenam? Com que língua falamos e escrevemos a nossa psicanálise - seja lá o que isso for - e com o que a ilustramos? O que fazemos com essa língua que vem do Outro teórico: fazemos dela a nossa, devorando-a antropofagicamente, ou mordemos a nossa própria e nos entregamos ao ventriloquismo? Ou pior, colocamos na boca dos nossos pacientes aquilo que Freud tomou emprestado da boca dos seus? Qual o preço das narrativas que assim silenciamos? Como diria António Vieira no "Sermão da terceira Dominga Post Epiphaniam", pregado na Sé de Lisboa por volta do ano de 1662 - alguns anos antes, portanto, de ser encarcerado pela Inquisição -: "as despesas de tudo isto [...] se veem tiradas e espremidas todas do sangue, do suor e das lágrimas dos vassalos [...], chorando os naturais para que se alegrem os estranhos”. Língua é mais que sangue.

Para a psicanálise, uma política linguística não teria como prescindir, então, reinstaurando o ato freudiano, de olhar para as nossas próprias tragédias 
quando nos preocupamos em pensar o analista em seu consultório, mas também na cidade, na praça, na rua... que me parecem mais interessantes que pólis, termo que lamentavelmente se vem convencionando utilizar no Brasil - e da qual estavam excluídos, por sinal, os estrangeiros, as mulheres e os escravizados. Será que olhamos nos olhos das nossas tragédias cotidianas quando pensamos em nossas poltronas e divãs, nas falas e textos que veiculamos, na teoria para a qual nos propomos a contribuir? Em que medidas essas tragédias são nossas? São, quem sabe, as que chegam aos nossos divãs, ou apenas as que chegam até nós pelos noticiários?

Ora, a localização geográfica, mas também o preço que praticamos em nossas clínicas peneiram invariavelmente as narrativas que chegam aos nossos consultórios. Quantos reais marcam a nota de corte da nossa escuta? E, para além da clínica pública - hoje em pauta após anos de apagamento na história da psicanálise (Danto, 2019) -, que real interesse temos nós de pensar uma formação menos elitista e menos homogênea, deixando de supor que quem não dispõe de capital é eventualmente o analisante, mas não o eventual analista em formação? Aqueles que vemos e reconhecemos como pares, de onde vêm e que língua falam? Qual o sotaque? Que cor de pele fazem ver, que sobrenomes fazem ouvir e com que gênero se identificam?

Uma política linguística para a psicanálise no Brasil não pode desviar dessas perguntas. Tampouco do fato de que a cada 23 minutos um jovem negro é assassinado no país; das torturas em supermercados; dos transeuntes desavisados que encontram balas perdidas. O genocídio do negro brasileiro escancara a nossa porta, enquanto entram pelas janelas o calamitoso primeiro lugar ocupado no ranking de assassinatos de pessoas trans, o preconceito arraigado no Sudeste contra os nordestinos, a violência sistemática contra a mulher - e sobretudo a mulher negra - e a espoliação dos povos indígenas. Violências e mortes físicas, decerto, como é de conhecimento amplo, mas também violências e mortes simbólicas que se acumulam há tempos.

Até o governo de Getúlio, a capoeira era criminalizada como ato de vadiagem desde o século XIX; e o samba, desde o início do XX. O ataque e a criminalização contra povos indígenas e seus defensores foram considerados os mais graves do mundo, conforme relatoria da Organização das Nações Unidas divulgada ano retrasado (Calazans, 2018). A criminalização da maconha, conhecida no Brasil Colônia como "fumo de negro", estende-se até os dias de hoje, e nasceu colada no combate a religiões de matriz africana (Barros; Peres, 2011). Em 2017, foi analisada pelo Senado Federal uma proposta de criminalização do funk como crime de saúde pública contra a criança, o menor adolescente e a família (Ideia Legislativa, 2017). E uma das questões do Enem 2018 que abordava o pajubá, dialeto utilizado por comunidades gays e trans - e com forte influência iorubá, diga-se de passagem -, gerou burburinho em todo país, recebendo críticas menções presidenciais. É como se não bastasse dizimar a carne sem, antes, ter garroteado bem o espírito. Língua é mais que sangue. 
"Foi a filha de um trabalhador. Ela fala inglês, tem aula de balé, tem aula de tudo, era estudiosa..." (Félix apud DeLuca, 2019). É com essa frase, dita pelo avô de Agatha Félix, assassinada no Rio de Janeiro em setembro passado, que encerro aqui este texto, escrito uma semana depois. Um eco de tantos estampidos, disparos e desfechos... e muito de Brasil. Um país que cada vez menos espera abrir a boca para calar a língua, não poupando o sangue quando divisa a pele. E a cada psicanalista fica o convite de abrir os ouvidos e, como diria Lacan em 1978, ver-se forçado - pois é preciso que se veja forçado a isso - a reinventar a psicanálise. Aqui, agora e sempre.

\section{Notas}

1 A dita "Lei de proteção ao sangue e à honra alemães" [ Gesetz zum Schutze des deutschen Blutes und der deutschen Ehre - Blutschutzgesetz].

2 Cumpre notar, quanto à língua geral, que "foi nas áreas mais afastadas do centro administrativo da Colônia (que era a Bahia) que se intensificou e generalizou [seu] uso". A língua brasílica era "língua comum entre os portugueses e seus descendentes predominantemente mestiços - e escravos (inclusive africanos), os índios tupinambá e outros índios incorporados às missões, às fazendas e às tropas: em resumo toda a população, não importa qual sua origem, que passou a integrar o sistema colonial” (Rodrigues, 1986, p.101).

3 Os dados sobre o número de línguas indígenas existentes hoje no Brasil não são exatos. O Museu Paraense "Emílio Goeldi" contabiliza 150; o Instituto de Estudos da Linguagem (Unicamp) e o Laboratório de Línguas Indígenas da Universidade de Brasília (UnB), por sua vez, com base nas projeções de Aryon Rodrigues, falam em 181. No entanto, o Censo de 2010, elaborado pelo IBGE, aponta a existência de 274 línguas faladas em território nacional por 305 povos indígenas diferentes.

\section{Referências}

ANCHIETA, J. de. Arte de grammatica da lingua mais usada na costa do Brasil. Leipzig: B. G. Teubner, 1876.

BARROS, A.; PERES, M. Proibição da maconha no Brasil e suas raízes históricas escravocratas. Revista Periferia, Duque de Caxias, v.3, n.2, jul.-dez., 2011. Disponível em: <doi.org/10.12957/periferia.2011.3953>. Acesso em: 13 jan. 2020.

CALAZANS, M. “Ataques e criminalização contra os povos indígenas e seus defensores no Brasil são os mais graves do mundo", afirma relatora da ONU. Conselho indigenista missionário, Brasília, 21.9.2018. Disponível em: <cimi.org.br/2018/09/ataques-e-criminalizacao-contra-os-povos-indigenas-e-seus-defensores-no-brasil-sao-os-mais-graves-do-mundo-afirma-relatora-da-onu/>. Acesso em: 13 jan. 2020.

DANTO, E. A. As clínicas públicas de Freud. Trad. Margarida Goldsztajn. São Paulo: Perspectiva, 2019.

DeLUCA, N. "Isso é confronto? A minha neta estava armada, por acaso?”, diz avô de Ágatha. Folha de S.Paulo, São Paulo, 22.9.2019. Disponível em: <wwwl folha.uol.com. 
br/cotidiano/2019/09/isso-e-confronto-a-minha-neta-estava-armada-por-acaso-diz-avo-de-agatha.shtml>.

DERRIDA, J. Geopsicanálise "and the rest of the world" [1981]. Trad. Paulo Sérgio de Souza Jr. In: SOUZA JUNIOR, P. S. de. (Org.) A psicanálise e os lestes. São Paulo: Annablume, v.2 [no prelo].

IDEIA LEGISLATIVA. Criminalização do funk como crime de saúde pública a criança aos adolescentes e a família - Sugestão n.17 de 2017. Disponível em: <www12.senado. leg.br/ecidadania/visualizacaoideia?id=65513>. Acesso em: 13 jan. 2020.

KLEMPERER, V. LTI: a linguagem do Terceiro Reich. Trad. Miriam B. P. Oelsner. Rio de Janeiro: Contraponto, 2009.

LACAN, J. 9e Congrès de l'École Freudienne de Paris sur La transmission. Lettres de l'École, Paris, v.25, n.2, 1979.

LÉVY, D.; REZNIK, S. Wo Es war... la langue - entrevista com Jean-Claude Milner. Trad. Paulo Sérgio de Souza Jr. Analytica, São João Del Rei, v.3, n.5, 2014. Disponível em: <www.seer.ufsj.edu.br/index.php/analytica/article/view/823>. Acesso em: 13 jan. 2020.

RODRIGUES, A. Linguas brasileiras: para o conhecimento das línguas indígenas. São Paulo: Loyola, 1986.

VIEIRA, A. Sermão da terceira Dominga Post Epiphaniam, na Sé de Lisboa (Portugal). In: Sermões. Porto: Lello \& Irmão, 1959. v.2.

RESUMO - Este artigo parte de aspectos linguístico-históricos gerais e se aproxima do caso brasileiro para pensar o papel do vernáculo como instrumento de colonização e a política de língua no Brasil. A partir da ideia de que a colonização do outro passa pela língua - e tendo em vista as especificidades linguísticas, raciais e socioeconômicas brasileiras -, procuramos trazer ao debate alguns dos efeitos da colonização em um campo no qual a linguagem tem um estatuto duplamente privilegiado, a saber: a tradução de textos psicanalíticos.

PALAVRAS-CHAVE: Política, Língua, Tradução, Psicanálise.

ABSTRACT - This paper starts with general linguistic-historical aspects and addresses the Brazilian case to reflect on the role of the vernacular as an instrument of colonization, and on language policy in Brazil. Because colonizing the other involves language, and because of the Brazilian linguistic, racial and socioeconomic specificities, we seek to bring to the debate some effects of colonization in a field where language has a doubly privileged status, namely: the translation of psychoanalytic texts.

KErWORDs: Politics, Language, Translation, Psychoanalysis.

Paulo Sérgio de Souza Junior é psicanalista, linguista e tradutor. Bacharel e doutor em linguística pelo Instituto de Estudos da Linguagem (Unicamp), com pós-doutoramento no Departamento de Ciência da Literatura da Universidade Federal do Rio de Ja- 
neiro. Foi professor associado do Departamento de Língua Romena e Linguística Geral da Universidade Alexandru Ioan Cuza (Iaşi). @ - contra_sujeito@yahoo.com.br / https://orcid.org/0000-0003-2393-5469.

Recebido em 14.1.2020 e aceito em 30.4.2020.

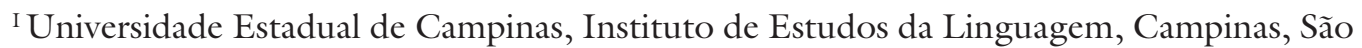
Paulo, Brasil. 
